it is difficult to explain how successful resuscitation is possible after 40 minutes' submersion. ${ }^{2}$ The reduced oxygen requirement in profound hypothermia has been suggested by some authors as the mechanism by which tissue viability is maintained in these circumstances, ${ }^{2}$ but this alone is an incomplete explanation, as for the submerged body to cool to a degree at which oxygen requirements are sufficiently reduced, heat transfer by mass flow-that is, circulation - must be present (a dead body cools relatively slowly). The degree of cooling encountered in our cases can be explained only by the fact that circulation was maintained for some or all of the period of submersion. The persistence of cardiac activity during such a prolonged period of apnoea supports the hypothesis that some protective mechanism may be present. We do not know whether ventricular fibrillation was present before resuscitative efforts were started and must concede that these efforts alone may have initiated the arrhythmia.

Our cases show yet again that successful resuscitation is possible after long periods of immersion and emphasise the importance of performing electrocardiography early in the immersion incident, preferably at the accident site, before death is pronounced.

${ }^{1}$ Modell $\mathrm{JH}$. The pathophysiology and treatment of drowning and neardrowning. Springfield, Illinois: CC Thomas, 1971:41-9.

2 Siebke H, Rød T, Braeivik H, Lynd B. Survival after 40 minutes submersion without cerebral sequelae. Lancet $1975 ; \mathrm{i}: 1275-7$.

3 Modell JH, Graves SA, Ketover A. Clinical course of 91 consecutive near-drowning victims. Chest $1976 ; 70: 231-8$.

${ }^{4}$ Ross DN. Problems associated with the use of hypothermia during cardiac surgery. Proc $R$ Soc Med 1957;50:76-8.

${ }^{5}$ Golden FStC. Death after rescue from immersion in cold water. $\mathcal{f} R \mathrm{Nav}$ Med Serv 1973;59:5-8.

(Accepted 6 May 1981)

Department of Medicine, Guy's Hospital, London SE1 9RT

M G HARRIES, MB, MRCP, lecturer

Institute of Naval Medicine, Alverstoke, Gosport, Hants PO12 2DL F ST C GOLDEN, MB, PHD, surgeon commander

King's College Hospital, London SE5 9RS

$M$ FOWLER, MB, MRCP, medical registrar

\section{Effect of nifedipine on bronchomotor tone and histamine reactivity in asthma}

Secretion of chemical mediators from mast cells and contraction of bronchial smooth muscle are two major components in the pathogenesis of asthma. Both processes depend on the transmembrane passage of calcium ions, and drugs that inhibit this might therefore be expected to be of value in asthma. Cinnarizine, an antagonist to calcium transport, has been shown to exert a beneficial effect in patients with chronic asthma, ${ }^{1}$ and verapamil, another calcium antagonist, prevents potassium- and serotonin-induced contraction of canine trachealis muscle. ${ }^{2}$ Nifedipine is a potent inhibitor of transmembrane calcium ion flux, and results of a recent study suggest that it prevents exercise-induced asthma. ${ }^{3}$ We therefore investigated the effect of nifedipine on resting bronchomotor tone and on histamine reactivity in patients with asthma.

\section{Patients, methods, and results}

We studied 10 patients, aged $25-60$ years, with chronic stable asthma. The protocol was approved by the hospital research ethics committee, and all subjects gave informed consent.

Each subject received either nifedipine $20 \mathrm{mg}$ or placebo in a randomised double-blind fashion on separate days and was instructed to bite the capsules and keep the fluid in the mouth as long as possible. Both active and placebo capsules had the same appearance and contained liquid with an identical peppermint taste.

Using a dry spirometer, we measured forced expiratory volume in one second $\left(\mathrm{FEV}_{1}\right)$, vital capacity (VC), and maximal mid-expiratory flow (MMEF) before and at $15,30,45$, and 60 minutes after the capsules were taken. Blood pressure and heart rate were also recorded. After the measure- ments at 60 minutes histamine reactivity was assessed by giving the subjects serial dilutions of histamine acid phosphate solution to inhale via a Wright nebuliser. The concentration of histamine producing a $20 \%$ fall in $\mathrm{FEV}_{1}\left(\mathrm{PC}_{20}\right)$ was calculated. Each subject received $200 \mu \mathrm{g}$ inhaled salbutamol at the end of the study.

The studies were performed in an air-conditioned laboratory under constant environmental conditions. Both tests were performed at the same time of day in each subject, and the subjects had not taken any medication for at least eight hours beforehand.

No subject complained of any side effects, and there were no significant changes in blood pressure or heart rate. The lung function results are summarised in the table. There was no significant difference in baseline

Mean $\pm S E M$ changes in tests of lung function during treatment with nifedipine and placebo

\begin{tabular}{lccccc}
\hline & Control & \multicolumn{5}{c}{ Minutes after taking capsules } \\
\cline { 2 - 5 } & \multicolumn{7}{c}{ Forced expiratory volume in one second $(l)$} \\
\hline Active & $1.63 \pm 0.21$ & $1.81 \pm 0.22$ & $1.92 \pm 0.21$ & $1.98 \pm 0.22$ & $1.93 \pm 0.23$ \\
Placebo & $1.61 \pm 0.16$ & $1.75 \pm 0.16$ & $1.78 \pm 0.17$ & $1.81 \pm 0.17$ & $1.86 \pm 0.17$ \\
Vital capacity $(l)$ \\
Active & $3.04 \pm 0.24$ & $3.29 \pm 0.22$ & $3.38 \pm 0.21$ & $3.44 \pm 0.20$ & $3.37 \pm 0.21$ \\
Placebo & $2.97 \pm 0.19$ & $3.17 \pm 0.19$ & $3.24 \pm 0.17$ & $3.37 \pm 0.21$ & $3.29 \pm 0.23$ \\
Maximal mid-expiratory flow $(l / s)$ & & \\
Active & $0.86 \pm 0.15$ & $1.01 \pm 0.17$ & $1.05 \pm 0.17$ & $1.17 \pm 0.21$ & $1.11 \pm 0.19$ \\
Placebo & $0.82 \pm 0.12$ & $0.88 \pm 0.12$ & $0.98 \pm 0.16$ & $0.95 \pm 0.12$ & $1.02 \pm 0.15$
\end{tabular}

spirometry between the days when nifedipine and placebo were taken. Although the increases in mean $\mathrm{FEV}_{1}$ and $\mathrm{MMEF}$ were both greater with nifedipine than placebo, an analysis of variance failed to show any significant difference between the two. $\mathrm{PC}_{20}$ was significantly greater $(\mathrm{p}<0.05$, paired $t$ test) after nifedipine $(0.42 \pm 0.14 \mathrm{mg}$ histamine $/ \mathrm{ml})$ than placebo $(0.15 \pm$ $0.03 \mathrm{mg}$ histamine $/ \mathrm{ml}$ ). All subjects showed a good bronchodilator response to inhaled salbutamol at the end of the study.

\section{Comment}

Although we were unable to show any significant bronchodilator activity for nifedipine, we showed that this drug provides a significant protective effect against histamine-induced bronchoconstriction. This suggests that it may have an effect on the contractility of bronchial smooth muscle, but the effect is too small to make oral nifedipine therapeutically useful in asthma. Our results clearly show, however, that nifedipine may safely be given to patients with asthma. Its clinical effectiveness in the treatment of angina is well documented, and there is some evidence that it produces an improvement in FEV when given to patients with angina and labile airways obstruction. ${ }^{4}$ Beta-adrenoreceptor antagonists have been the mainstay of antianginal treatment in recent years, but the use of such drugs in patients with asthma may be extremely hazardous. ${ }^{5}$ Patients with angina and coexistent asthma should be treated with nifedipine for their angina in preference to beta-blockers.

We are grateful to Dr G Macdonald, of Bayer UK Limited, for supplies of nifedipine and placebo capsules.

${ }^{1}$ Emanuel MB, Chamberlain JA, Whiting S, Rigden BG. Cinnarizine in the treatment of chronic asthma. Br F Clin Pharmacol 1979;7:189-95.

2 Coburn RF. The airway smooth muscle cell. Fed Proc 1977;36:2692-7.

3 Cerrina J, Denjean A, Alexandre G, Lockhart A, Duroux P. Inhibition of exercise-induced asthma by a calcium antagonist, nifedipine. Am Rev Resp Dis 1981;123:156-60.

${ }^{4}$ Jaiprakash SS, Sahay JN, Chatterjee SS, Macdonald G. Efficacy of nifedipine in the treatment of angina pectoris and chronic airways obstruction. Postgrad Med f 1980;56:624-8.

${ }^{5}$ Raine JM, Palazzo MG, Kerr JH, Sleight P. Near-fatal bronchospasm after oral nadolol in a young asthmatic and response to ventilation with halothane. Br Med f 1981 ;282:548-9.

\section{(Accepted 13 May 1981)}

Department of Medicine, Royal Postgraduate Medical School, Ham mersmith Hospital, London W12 0HS

D O WILLIAMS, MRCP, honorary senior registrar

P J BARNES, MRCP, senior registrar

H P VICKERS, research assistant

MICHAEL RUDOLF, MRCP, honorary senior lecturer 